\title{
COLONIC PERFORATION IN AN INFANT FOLLOWING INADVERTENT USE OF PHOSPHATE ENEMA
}

\author{
Soumyodhriti Ghosh ${ }^{1}$, Kumar Mitrabhanu2, Smriti Nath², Priya Amitabh². \\ ${ }^{1}$ Pediatric Surgery Unit, Abhishek Child Care Hospital, Jamshedpur, India, \\ ${ }^{2}$ Department of Pediatrics, Tata Motors Hospital, Jamshedpur, India.
}

\section{KEYWORDS}

colonic perforation; enema; trauma; infant.

\section{ARTICLE HISTORY}

Received 21 November 2020

Accepted 26 December 2020

\section{TO THE EDITOR,}

Beyond neonatal period, acute surgical abdomen in infancy is usually due to intussusception, Hirschsprung disease, incarcerated hernia or volvulus. ${ }^{1,2}$ Traumatic perforation of the colon or rectum as a cause is rarely reported. ${ }^{1}$ We describe an unusual case of acute abdomen due colonic perforation caused by incompetent use of enema in an infant.

An 8-month-old female infant was brought to emergency with complaints of not passing stool for three days and progressive distension of the abdomen for 24 hours. The infant was previously healthy with uneventful birth and postnatal history. At admission, the infant was sick, listless with signs of poor perfusion and a tense abdomen. By revisiting the history,

we found that over the counter purchased, sodium phosphate proctoclysis enema was given to her at home a day before to treat her 'constipation'. X-ray abdomen showed massive pneumoperitoneum. On exploration, a full thickness fresh perforation of $0.5 \mathrm{~cm} \times 0.5 \mathrm{~cm}$ was noted in distal sigmoid colon. Primary repair closure was done and post-operative period was uneventful.

Traumatic perforation of the colon or rectum in infants is exceedingly rare. Most cases are attributed to direct injury or distal mechanical obstruction. Trauma infliction may be due to rectal thermometer usage, cleansing enema for constipation, barium enema contrast study. ${ }^{1}$ In our case, perforation of the colon is believed to be due to i) mechanical trauma from the firm enema tip or ii) increased hydrostatic pressure..$^{1,2,3}$ Also, the shorter distance from the anal verge to the sigmoid colon in infants make them more prone to injury particularly, if we consider that the procedure is done on a struggling and uncooperative infant. ${ }^{4}$ Furthermore, sodium phosphate enema is contraindicated below two years of age as it is known to cause lethal hyperphosphatemia with subsequent hypocalcemia and acidosis. If absolutely indicated with predisposing causes, glycerine suppository is preferred. ${ }^{5}$

Over-the-counter proctoclysis enema administration is extremely rampant. Although considered too easy a

Address for Correspondence: Soumyodhriti Ghosh, Pediatric Surgery Unit, Abhishek Child care Hospital, Jamshedpur 831011.

Email: drsghosh.surg85@gmail.com

(C)2021 Pediatric Oncall procedure, the side effects can be catastrophic. Hence the need for trained professionals cannot be over emphasized to perform such procedures in children.

\section{Compliance with Ethical Standards}

Funding None

Conflict of Interest None

\section{References:}

1. Singh $Y$, Singh $N$, Narasimhan KL, Mitra SK. Saline enemas-A potential hazard in newborns. Indian Pediatr. 1998;35:799-800.

2. Mehrabani S, Gharehdaghli L, Esmaeili Dooki MR, Asghari $Y$, Hadipour A, Moslemi L. Idiopathic Perforation of the Sigmoid Colon in a 2.5 Years Old Girl: A Case Report. International J Pediatr. 2017;5:5709-5713.

3. Saraç M, Bakal Ü, Aydın M, Tartar T, Orman A, Taşkın $E$, et al. Neonatal gastrointestinal perforations: the 10year experience of a reference hospital. Indian J Surg. 2017;79:431-436.

4. Grover J, Ali Q. A study of peritonitis in newborns and infants. Global Journal For Research Analysis (GJRA). 2018;7:49:53.

5. Poddar U. Approach to constipation in children. Indian Pediatr. 2016;53:319-327. 